\title{
TRABALHO E HISTÓRIA DO PENSAMENTO GEOGRÁFICO NOS MEANDROS DA GEOGRAFIA CRÍTICA
}

\section{Labor and history of geographical thinking in the means of critical geography}

\author{
Jânio Roberto Diniz dos Santos ${ }^{1}$ http://orcid.org/0000-0003-4972-7684 \\ Suzane Tosta Souza ${ }^{2}$ http://orcid.org/0000-0001-8658-0189
}

1 - Doutor em Geografia, Professor Titular do Departamento de Geografia- UESB- Brasil, email - jandiniz@ yahoo.com.br
2- Doutora em Geografia, Professora Titular do Departamento de Geografia- UESB- Brasil, email - suzanetosta@gmail.com

\begin{abstract}
Resumo
O presente artigo visa refletir sobre a importância da categoria trabalho na produção e no pensamento geográfico brasileiro, com destaque as reflexões realizadas no âmbito da geografia crítica fundamentada na leitura e no método do materialismo histórico dialético, debate efervescente na geografia brasileira nas décadas de 1980 e 1990 e, em menor proporção, nas décadas posteriores. O presente artigo vem no sentido de reafirmar a importância da categoria trabalho nos estudos em geografia e nas reflexões dos pensadores brasileiros fundamentados em uma perspectiva de compreensão e transformação da realidade social. é partindo dessas reflexões que apontaremos algumas das leituras realizadas pelo grupo de pesquisadores do laboratório de estudos agrários e urbanos/UESB cuja categoria trabalho torna-se fundamental para se compreender os diferentes processos de produção do espaço na atualidade, em destaque o contexto de crise estrutural e de tentativa de reestruturação da produção de capital e seus rebatimentos no espaço e na produção do pensamento geográfico.
\end{abstract}

Palavras-chave: Trabalho, Pensamento Geográfico, Produção do Espaço.

\begin{abstract}
This article aims to reflect on the importance of the category labor in production and Brazilian geographic thought, with emphasis on the reflections carried out in the context of critical geography based on the reading and the method of dialectical historical materialism, an effervescent debate in Brazilian geography in the 1980s and 1990, and to a lesser extent in the following decades. The present article comes to reaffirm the importance of the category work in the studies in geography and in the reflections of the Brazilian thinkers based on a perspective of understanding and transformation of the social reality. it is starting from these reflections that we will point out some of the readings made by the group of researchers of the laboratory of agrarian and urban studies-UESB, whose category work becomes fundamental to understand the different processes of production of the space in the present time, emphasizing the context of structural crisis and an attempt to restructure capital production and its repercussions in space and in the production of geographic thought.
\end{abstract}

Keywords: Labor, Geographical Thought, Space Production.

V. 01, n. 01, 2017 http://periodicos2.uesb.br/index.php/geo 


\section{Introdução}

Refletir sobre a importância da categoria trabalho no Pensamento Geográfico brasileiro, com destaque as análises realizadas no âmbito da Geografia Crítica e seus efervescentes debates, constitui-se no objetivo central deste artigo; bem como destacar os debates mais atuais fundamentados na categoria trabalho enquanto fundante na produção geográfica, em sua reaproximação com a teoria crítica marxista, com destaque para os grupos de pesquisa e de pesquisadores em diversos locais do país. Nesse propósito, é enfatizada a realidade dos caminhos percorridos por pesquisadores que, partindo das reflexões de Karl Marx, Georges Lukács e mais recentemente Istvan Mészáros, reafirmam o trabalho enquanto categoria fundante na produção do espaço geográfico, portanto para a constituição de um pensamento geográfico que preze pela compreensão da realidade social e suas contradições, quanto, em alguns momentos, pela perspectiva de transformação revolucionária da sociedade.

Em um primeiro momento, será revisitada a produção geográfica fundamentada na centralidade e compreensão do trabalho enquanto categoria fundante para a análise da realidade espacial; assim como o destaque para alguns autores brasileiros que introduzem tal debate no âmbito do pensamento geográfico brasileiro.

Em um segundo momento, fundamentados na realidade social de crise e reestruturação que marcam o momento atual de expansão e acumulação capitalista, reforça-se a importância das análises geográficas que fundamentadas na teoria e no método de Marx, como forma de fomentar um pensamento geográfico eminentemente crítico e revolucionário.

O artigo apresentado pretende ser um pontapé inicial para reflexões no âmbito de um pensamento geográfico e de uma geografia da práxis, fundamentada na necessidade de compreensão/superação da realidade societal, que reafirma a retomada do debate crítico tão forte no contex to do pensamento geográfico brasileiro nas décadas de 1980 e 1990 e, mais recentemente em processo de 'refluxo', conforme expressão utilizada por Carlos (2007). Nesse processo, ressalta que, a retomada dos debates marxianos, pressupõe para o geógrafo as reflexões sobre a categoria trabalho, enquanto central na compreensão da realidade e na produção do espaço geográfico, portanto da possibilidade de se construir um pensamento geográfico para a transformação da realidade social.

O Trabalho enquanto categoria no Pensamento Geográfico Brasileiro 
Revisitando um estudo realizado por Francesconi (2006) afere-se que as discussões sobre a realidade em mutação no mundo do trabalho não é tema novo no pensamento geográfico, quando a autora aponta como pioneiro um estudo realizado pelo geógrafo francês Pierre George (1978) intitulado Les Populations actives: essai sur la géographie du travail. Ressalta-se que, conforme Moraes (1999), o autor francês Pierre George pode ser considerado um dos baluartes do pensamento crítico que se aproxima da teoria crítica e do método desenvolvido por Marx, debate que na Geografia se consolida no contexto pós segunda guerra mundial, junto com autores como Yves Lacoste, Bernard Kayser e Raymond Guglielmo e que se expande em finais da década de 1970, em um contexto mundialmente marcado pelo início de uma crise estrutural do sistema do capital, segundo analisa Meszáros (2002). Ainda de acordo com o geógrafo brasileiro Antonio Carlos R. Moraes (1999) é notável a influencia desses mestres franceses no pensamento geográfico brasileiro, com destaque a participação mais direta desses pensadores em escolas como a Universidade de São Paulo. Tais ideias, acredita-se, frutificaram um campo de debate que traz oacategoria trabalho para as reflexões dos geógrafos brasileiros, em um contexto interno marcado pela luta em prol da redemocratização frente ao regime militar em curso e retomada dos movimentos sociais e sindicais.

É nesse contexto que Francesconi (2006, p. 02) aponta que:

Por um lado, a Geografia apreendeu o Trabalho em sua divisão internacional e regional para a compreensão das desigualdades internacionais e inter-regionais. Além disso, o Trabalho constitui-se em conceito fundamental para a explicação do espaço como produto social o qual tanto no urbano quanto no rural reproduz-se contraditoriamente tal como a totalidade social da qual faz parte.

Além do trabalho, outras categorias como modo de produção, forças produtivas, relações de produção passam a compor o leque analítico de alguns dos geógrafos brasileiros, a exemplo de Ruy Moreira. O debate em torno da categoria trabalho no contexto de produção do pensamento geográfico é trazido por esse autor tanto no livro $\mathrm{O}$ que é Geografia, publicado no ano de 1981, quanto em diversos textos publicados posteriormente, a exemplo do texto "A Geografia serve para desvendar máscaras sociais", como parte da coletânea Geografia Teoria e prática, publicada no ano de 1982, em que discute o conceito de formação econômico-social, de forte influência leninista. 
A natureza social do espaço geográfico decorre do fato simples de que os homens têm fome, sede e frio, necessidades de ordem física decorrentes de pertencer o homem ao reino animal, ponte de sua dimensão cósmica. No entanto, à diferença do animal, o homem consegue os bens de que necessita intervindo na "primeira natureza", transformando-a. Transformando o meio natural, o homem transformase a si mesmo. Ora, como a obra de transformação do meio é uma realização necessariamente dependente do trabalho social (a ação organizada da coletividade dos homens), é o trabalho social o agente de mutação do homem, de um "ser animal" para um "ser social", combinando estes dois momentos em todo o decorrer da história humana (MOREIRA, 1982, p. 7).

Já nos anos 2000 Moreira, partindo da teoria do Valor de Marx, assim como bastante influenciado pelas leituras do filósofo húngaro Istvan Meszáros e do sociólogo brasileiro Ricardo Antunes, destaca a emergência da compreensão do mundo do trabalho na Geografia em dois níveis: a relação metabólica do homem com o meio natural e a relação do homem com a sociedade. Assim, assume a emergência de uma Geografia do trabalho tendo o valor como elemento teórico de referencia e as recentes transformações no mundo do trabalho que influenciam a produção geográfica. Para ele, é o valor quem comanda o mundo do trabalho, no entanto cabe considerar que a forma do valor varia com o tempo histórico. Assim sendo, nas sociedades mais antigas torna-se visível o valor de uso das mercadorias, algo que se inverte na sociedade capitalista moderna, em que o valor de uso é subsumido ao valor de troca, adentrando o debate do sistema de mediações estabelecidas entre a sociedade e a natureza pela via do trabalho.

Moreira (2001) considera que nas sociedades mais antigas o trabalho aparece como relação metabólica, caracterizada pelo intercâmbio entre o homem e a natureza, em que o primeiro impulsiona, controla e regula esse intercâmbio, produzindo valores de uso, atuando sobre a natureza externa e modificando-a, ao mesmo tempo modificando sua própria natureza, produzindo a natureza socializada (ou segunda natureza). A emergência do valor de troca modifica, por completo, essa relação. Com base em Marx (1984) o autor arremata que: "o valor nasce do desenvolvimento das trocas" (p. 11). Inicialmente essas trocas ocorrem por meio do intercâmbio de valores de uso realizado pelos produtores diretos; no entanto, quando as trocas se tornam mais generalizadas a equivalência dos valores dos bens trocados torna-se uma necessidade. Assim, "a própria experiência prática dos produtores leva-os a comparar as quantidades de horas-trabalho gastas na 
produção de valor-de-uso como referência no ato da troca, nascendo o conceito de valor de troca" (p. 11) ${ }^{3}$.

É nessa relação que caracteriza a sociedade capitalista que o dinheiro emerge como recurso contábil do valor, e a quantidade de moedas passa a representar a quantidade de horas-trabalho (estabelece-se, assim, o quantum de trabalho necessário a produção de uma dada mercadoria, mas não apenas individualmente, senão em comparação com o mesmo processo referente a produção de outra, e de tantas outras mercadorias). É desse modo que ocorre uma mudança (não apenas quantitativa, mas qualitativa) na relação de intercâmbio homem-natureza, para uma relação de troca mercantil. Essa relação adquire maior proporção nas sociedades nascidas da revolução industrial. Para Moreira (2001), nesse momento em diante vai ocorrer uma separação entre a natureza e o trabalho (quando a primeira é apropriada privadamente) e uma separação entre a população e o trabalho, na conversão do trabalhador em força de trabalho (fator de produção, de acordo com Meszáros, 2002) para produzir o valor. Esses processos são fundamentais para se estabelecer, segundo o autor, o processo de compreensão da "concreção espacial". Essa referenda-se na sociedade do trabalho, que caracteriza o capitalismo industrial avançado e que, contraditoriamente, estilhaça a existência humana, configurando-se em um processo de desumanização do sujeito social que trabalha. E adquire nova dimensão em período posterior, na metade da segunda revolução industrial à emergência da terceira com a hegemonia do capital financeiro, mediante o predomínio da esfera da circulação, trazendo mudança ao próprio conceito do valor, com novas investidas para o mundo do trabalho ${ }^{4}$.

O debate sobre a teoria crítica marxista e a centralidade da teoria do valor trabalho no Brasil, em destaque os teóricos da Geografia, sofre ainda a influência direta da analise desenvolvida pelo filósofo francês Henri Lefebvre, que em sua perspectiva de superar a leitura estática euclidiana e cartesiana sobre o espaço passa a formular o conceito de produção do espaço, cujo fundamento se estabelece através do trabalho, não o trabalho

\footnotetext{
${ }^{3}$ Em recente curso realizado com o Prof. Dr. Sérgio Lessa (UFAL) sobre Ontologia em George Lukács esse processo de aumento considerável do excedente e intensificação da troca, só se torna possível dadas as condições históricas verificadas no contexto dos séculos XVIII e XIX, com destaque aos processos de Revolução Burguesa e Revolução Industrial, em que se pode buscar os elementos para se compreender a passagem de um longo período da história humana marcado pela escassez, para um momento que passa a se definir pela abundância.

4 Acrescenta-se, contudo, que diferente de determinadas análises que apontam a financeirização da economia como um processo quase que autônomo das contradições postas no processo de extração do valor, reforça-se a centralidade do processo produtivo, em que se estabelece de forma mais intensa a extração de mais trabalho - na mudança da composição orgânica do capital - via expansão de seu caráter constante, intensificando - ao invés de eliminando - as contradições capital versus trabalho.
} 
em seu sentido restrito, enquanto materialização das atividades produtivas no espaço, mas enquanto resultante da própria história das sociedades, ao longo do tempo. Ou seja, o trabalho enquanto princípio gerador do homem. De acordo com Lefebvre (2001, p. 37 39) apud Godoy (2008, p. 126):

(...) a 'produção' envolve não somente o sentido econômico do termo, mas o sentido da filosofia inteira: produção de coisas (produtos) e de obras, de idéias e de ideologias, de consciência e de conhecimento, de ilusões e de verdades. (...) quem diz produção diz também 'reprodução', ao mesmo tempo física e social: reprodução do modo de vida.

Assim, Godoy (2008, p. 126), com base na análise Lefebvriana acrescenta que:

(...) o Trabalho enquanto categoria de análise não se reduz a exploração apenas da natureza objetiva das condições materiais e imateriais da produção em geral, mas a compreensão do que está além da exteriorização da ideologia e da objetivação das formas concretas, o que conduz à compreensão da própria gênese cultural do homem. $\mathrm{O}$ homem histórico, neste caso, resulta do seu próprio trabalho.

Ou seja, o conceito Lefebvriano possui sentido histórico e sociocultural, por conter uma dimensão temporal. Partindo desse argumento, reforça-se a relevância da categoria trabalho enquanto central na compreensão do processo de produção do espaço geográfico, e na construção de um pensamento geográfico crítico da realidade social, que se estabelece, historicamente, através da relação sociedade-natureza mediada pelas relações de trabalho estabelecidas. Assim, o homem, que historicamente desenvolve relações sociais, por meio do trabalho, entra em contato com a natureza, transformandoa em natureza humanizada, ou segunda natureza, ou seja, natureza produto do trabalho. Ai reside à essência de toda natureza humana e da Geografia enquanto ciência. Nesse sentido, a geógrafa Lenyra R. da Silva (2001, p. 50) arremata que:

O espaço geográfico constituído de totalidades capitalistas e nãocapitalistas tem na produção-reprodução realizada por meio do trabalho dos homens dialeticamente coisificados para o sistema e humanizados para si mesmos, onde a luta da natureza humana pela plenitude de vida se dá dentro e fora da atividade produtiva, dentro e fora de si mesmos, do seu corpo, da sua natureza. O resultado do trabalho humano, isto é, fração da natureza humana, objetivada na coisa feita ou produzida, percorre o mundo inteiro. A realização de um determinado trabalho poderá se dá muito distante do local onde o 
trabalhador produziu ou prestou um serviço qualquer, numa totalidade submetida a outra sociedade, a outro modo de produção.

Tal debate, que busca compreender o espaço geográfico enquanto produto do (e condição para o) trabalho humano em uma sociedade dividida em classes sociais tornase mais evidente na ciência geográfica a partir da década de 1950 em diante, com o movimento de renovação que trazia, em uma de suas matrizes, o pensamento crítico marxiano na compreensão das contradições do modo de produção capitalista. Além disso, buscava-se, naquele momento histórico, realizar uma revisão radical da Geografia praticada até então ancorada, sobretudo, no positivismo lógico e sua nova linguagem. $\mathrm{O}$ pensamento crítico passa a influenciar, sobretudo, os geógrafos brasileiros, que passam a adotar como fundamental a compreensão do espaço geográfico por meio das contradições existentes no processo de produção da vida social. Em tal análise, pode-se destacar os estudos desenvolvidos por David Harvey, inicialmente na obra A Justiça Social e a Cidade (1980) e em debates mais recentes como: Condição Pós-Moderna (1993) e Para entender o Capital (2013 e 2014). No Brasil pode-se destacar os estudos de Ana Fani Carlos, Ariovaldo Umbelino de Oliveira, Lenyra Rique da Silva, dentre outros.

De acordo com Carlos (2001),

O fio condutor da análise reside na tese segundo a qual, ao produzir sua vida (sua história, a realidade), a sociedade produz, concomitantemente, o espaço geográfico. Tais condições são produzidas pelo trabalho como atividade humana, logo, o desvendamento da atividade do trabalho considerado como processo produtor do espaço geográfico é o ponto de partida e permite discutir, de um lado, a articulação entre atividades produtivas e não-produtivas no conjunto da sociedade, e de outro, a materialização espacial deste processo, cujo movimento fundamenta-se na contradição entre produção espacial coletiva e apropriação privada". (CARLOS, 2001, p. 63).

Portanto, para a teoria crítica marxiana o trabalho sempre foi tratado como central na compreensão da realidade e das iniquidades provocadas pelo modo capitalista de produção em seu processo de realização histórica. No estudo da Questão Agrária, e da Geografia Agrária mais especificamente, Ariovaldo Oliveira (2007) retoma a análise do circuito completo do capital, na compreensão da realidade geográfica, apontando que: 
A lógica do desenvolvimento do modo capitalista de produção é gerada pelo processo de produção propriamente dito (reprodução ampliada/extração da mais-valia/produção do capital/extração da renda da terra), circulação, valorização do capital e reprodução da força de trabalho. É essa lógica contraditória que constrói/destrói formações territoriais em diferentes partes do mundo ou faz com que frações de uma mesma formação territorial conheçam processos desiguais de valorização, produção e reprodução do capital, conformando as regiões" (OLIVEIRA, 2007, p.75).

Para tanto, há que se compreender as contradições existentes no processo produtivo que em uma sociedade composta por classes sociais antagônicas permite-nos apreender, conforme apontado por Marx (1984), que a contradição fundamental reside no caráter social da produção e a apropriação individual de seus resultados, contraditoriamente apropriado por aqueles que detém o controle dos meios de produção. Se efetiva na separação entre o trabalhador e os instrumentos de trabalho, em que não resta ao trabalhador "livre", ou melhor, desprovidos dos instrumentos de produção, que pertence ao capitalista (proprietário dos meios de produção) e aos proprietários fundiários (proprietários da terra) alternativa a são ser a venda de sua força de trabalho, tornando-se, cada vez mais, móvel para produzir capital (GAUDEMAR, 1977). A "aparente relação de igualdade" entre proprietários e não-proprietários dos meios de produção, desmorona-se na realidade através da qual os produtores da riqueza - os trabalhadores, não se apropriam da riqueza produzida.

Essas contradições no processo produtivo são apontadas por Marx desde os escritos elaborados em sua juventude, quando nos Manuscritos Econômicos Filosóficos, de 1844, destaca que:

$\mathrm{O}$ trabalhador se torna tanto mais pobre quanto mais riqueza produz, quanto mais a sua produção aumenta em poder e extensão. $\mathrm{O}$ trabalhador se torna uma mercadoria tão mais barata quanto mais mercadorias cria. Com a valorização do mundo das coisas (Sachenwelt) aumenta em proporção direta a desvalorização do mundo dos homens (Menschenwelt) (...). Esse fato nada mais exprime, senão: o objeto (Gegenstand) que o trabalho produz, o seu produto, se lhe defronta como um ser estranho, como um poder independente do produtor (...). (..) Sim, o trabalho mesmo se torna um objeto, do qual o trabalhador só pode se apossar com os maiores esforços e com mais extraordinárias interrupções. A apropriação do objeto tanto aparece como estranhamento (Entfremdung) que, quanto mais objetos o trabalhador produz, tanto menos pode possuir e tanto mais fica sob o domínio do seu produto, do capital. (MARX, 2004, p. 80/81). 
Na relação desigual e contraditória que se estabelece na produção da mercadoria, o trabalhador se defronta com o produto do seu trabalho como um objeto que lhe é absolutamente estranho, e assim sendo: "quanto mais o trabalhador se desgasta trabalhando (ausarbeitet)" mais poderoso se torna o mundo alheio que ele cria diante de si e, ao mesmo tempo, mais pobre ele se torna, no seu mundo interior. O seu trabalho ao se tornar objeto possui, "uma existência externa (aussern), que existe fora dele, independente e estranha a ele".

A contradição só se torna perceptível, à medida em que se compreende que o que o trabalhador recebe sob a forma de salário é infinitamente menor do que ele de fato produziu. Esse mais-trabalho, que representa a quantidade de horas de trabalho não pagas ao trabalhador é apropriada pelo capitalista. Ao trabalhar por um salário esse acaba por aumentar a riqueza do capitalista, ao passo em que despende parte de sua energia e sua vida no processo produtivo.

\section{A subsunção do trabalho ao capital e seus rebatimentos na produção} geográfica

A referida análise parte do entendimento que os rebatimentos da crise estrutural do capital - que se arrasta desde a década de 1970, possuem rebatimentos desastrosos para os sujeitos sociais que trabalham, uma vez que a intensificação da produção, mediante expansão do capital constante, leva os trabalhadores - da condição de exército de reserva que ora ou outra pode vender sua força de trabalho - a condição de supérfluos, descartáveis para o capital. Entretanto, essas expressões representam a plena possibilidade de uma maior exploração da parcela dos sujeitos que conseguem se manter no processo produtivo, repercutindo em controle sobre o salário recebido (senão rebaixamento), bem como na intensificação da degradação das condições de trabalho, concretizando ainda mais a subsunção real do trabalho ao capital.

Para tratar de questões referentes ao atual estágio de desenvolvimento das forças produtivas, nos ancoramos em István Mészáros (2002), sobretudo na obra Para além do Capital (1995) e no Brasil nas reflexões de Ricardo Antunes (2002). Estes apontam que o sistema de metabolismo societal do capital, resultado da divisão social, vai promover a subordinação estrutural do trabalho ao capital. Para explicar como esse processo ocorre 
apontam que um sistema de mediações de segunda ordem sobredeterminou suas mediações básicas primarias, ou seja, suas mediações de primeira ordem.

Sobre isso Antunes (2002, p. 19) acrescenta que, genericamente, esse sistema de mediações de primeira ordem tem por finalidade e "a preservação das funções vitais de reprodução da reprodução individual e societal", no qual os seres humanos são considerados ainda parte da natureza, se utilizando dessa para realizar suas necessidades elementares. O homem enquanto parte da natureza, é compreendido enquanto condição ontológica humana, através do qual o intercâmbio comunitário com a natureza volta-se para produzir bens requeridos para a satisfação das necessidades humanas, visando o atendimento da reprodução social.

Na sociedade sob a égide do capital, esse sistema de primeira ordem de mediações é subsumido por outro sistema de mediações de segunda ordem que pressupõe $o$ estabelecimento de hierarquias estruturais de dominação e subordinação, que caracteriza a ordem societal de controle sob a égide do capital, que se segundo Mészáros apud Antunes (2002 p.20) representa a introdução de "elementos fetichizadores e alienantes de controle social metabólico"

É partindo dessa realidade que o capital é denominado por Meszáros (2002) como um modo e meio totalizante e dominante de mediação reprodutiva que subordina todas as funções reprodutivas sociais, cuja finalidade é expandir o valor de troca, para todas as necessidades desde as mais básicas as mais variadas atividades de produção, ou seja, representa a "completa subordinação das necessidades humanas à reprodução do valor de troca” (MÉSZÁROS apud ANTUNES, 2002, p. 21). O valor de uso torna-se subordinado ao valor de troca, em que os homens não mais produzem para a satisfação de suas necessidades vitais, mas para a satisfação dos detentores dos meios de produção - a classe dos capitalistas que objetivam o lucro.

Ao passo que a divisão do trabalho que caracterizava o sistema de mediações de primeira ordem baseava-se na função reguladora básica, o capital impõe uma estrutura de mando vertical pautada na divisão hierárquica do trabalho, voltada à necessidade continua e crescente de valores de troca. (ANTUNES, 2002).

De acordo com Mészáros (1999, apud Antunes 2002 p. 20), essa ordem sociometabólica do capital pressupõe a existência de alguns elementos, tais quais: a) a separação e alienação entre trabalhador e os meios de produção; b) a imposição dessas condições objetivadas e alienadas sobre os trabalhadores; c) a personificação do capital como valor egoísta voltado ao atendimento expansionista do capital; d) a personificação 
do trabalho, ou seja, dos operários como trabalho, dependente do capital historicamente dominante, fato que reduz a identidade do sujeito desse trabalho as funções produtivas. Assim, "as funções produtivas e de controle do processo do trabalho social são radicalmente separadas entre aqueles que produzem e aqueles que controlam" Compreende-se que o espaço geográfico, sendo produto histórico e social, vai reproduzir tais contradições da sociedade dividida em classes sociais, materializando as ações contraditórias do metabolismo de reprodução do capital, que se referenda nos espaços de produção da riqueza, que não se converte em espaços de riqueza da produção, e que reproduz, igual e contraditoriamente, os espaços da miséria, como condição a reprodução do mais valor.

É nesse propósito que Meszáros (2002) é enfático ao afirmar que é impossível se pensar na emancipação do trabalho sem superar o capital e o Estado. Esses defeitos estruturais do sistema de metabolismo social do capital, que se manifesta, dentre outras coisas, na separação entre produção e controle, quando esses adquirem uma independência "problemática" que se efetiva no exacerbado "consumismo" em determinados partes do mundo e por outro lado, se reproduz na mais desumana negação da satisfação das necessidades básicas para milhares de seres; demonstrando assim que a "força de trabalho total da humanidade encontra-se submetida aos imperativos alienantes de um sistema global de capital” (MESZAROS apud ANTUNES, 2002, p. 24). O espaço geográfico é produto e condição dessa relação desigual e contraditória.

Considera-se, portanto que, sob a ótica do capital, o trabalho que deveria voltar-se a satisfação daqueles que trabalham acaba sendo apropriado por aqueles que detêm os meios de produção, que se apropriam do produto do trabalho e os transforma em mercadoria, valores de troca. Assim, Oliveira (2007, p. 39) tomando por base o estudo realizado por Smith (1988) arremata que:

(...) sob o sistema capitalista, a apropriação e produção da natureza têm a materialidade social do processo de produção de mercadorias, reificado, alienado, oriundo da história dos homens: toda natureza é assim um produto social. Segundo Smith (1988), a produção da natureza é também produção do espaço geográfico expressa no desenvolvimento desigual do capitalismo. Esse desenvolvimento desigual é a expressão geográfica das contradições do capital, a fixação geográfica do valor de uso e do valor de troca. À medida que o processo de acumulação se intensifica, igualmente se intensificam as tendências à igualização e à diferenciação da produção capitalista do espaço. 
Portanto, as expressões geográficas das contradições do capital torna-se indispensável a elaboração de um discurso e um pensamento geográfico crítico e de superação da realidade societal.

\section{O Trabalho na Produção e no Pensamento Geográfico na atualidade}

Considera-se que o fundamento teórico metodológico e a práxis revolucionária desenvolvida por Karl Marx e demais marxistas trazidos para a Geografia, com destaque para o Movimento de Renovação Crítica, são fundamentais a leitura geográfica da realidade - que preze por desvelar as contradições sociais e a construção de um mundo mais justo. Tal debate, que foi tão efervescente nas décadas de 1980/90, tem sido mantido e mesmo ampliado por geógrafos que mantêm sua perspectiva analítica fundamentado na teoria e no método crítico. As discussões mais atuais são reforçadas por grupos de Pesquisa que evidenciam o trabalho como fundante do ser social, ao reforçar a indissociabilidade dessa realidade e a produção do espaço ao longo do processo histórico. Neste propósito, o debate chega ora a propor uma possível Geografia do Trabalho, ora retomando o tripé Estado, Capital e Trabalho, como centrais à análise geográfica - em que se pese o acirramento das contradições capital versus trabalho em tempos de crise e reestruturação do sistema sociometabólico do capital.

Desse modo, considera-se fundamental o debate que enfatiza a relação entre a teoria marxista e a produção teórica da Geografia crítica, bem como a mesma influencia o pensamento geográfico brasileiro no contexto do movimento de renovação crítico da Geografia e nas décadas posteriores. Além disso, cabe considerar, nos debates mais recentes da produção geográfica - em que se pese a reafirmação da teoria crítica marxista - como diversos geógrafos fundamentam (através de análises individuais ou via grupos de pesquisa) a relevância da categoria trabalho para a compreensão do pensamento geográfico, marcado também pela ascensão de outras matrizes interpretativas.

Ao analisar a introdução da categoria trabalho no pensamento geográfico, Léa Francesconi (2006 p. 1) esclarece que é nas últimas décadas do século XX que o ressurgimento dessa temática adquire importância fundamental, quando as mudanças no mundo do trabalho atingem de forma mais direta a sociedade brasileira e "o desemprego revela-se como ameaça crescente ou presença concreta para a sociedade brasileira inserida no mercado de trabalho no capitalismo desde o século XX". Daí aponta a 
emergência de uma Geografia do Trabalho, mediante a preocupação demonstrada por grande parte dos geógrafos em compreender as repercussões materiais das transformações ocorridas no mundo do trabalho. Entretanto, ainda considerando a emergência de uma Geografia do Trabalho, Thomaz Junior (2004, p. 10) arremata que não se trata, simplesmente, de constituir mais um recorte disciplinar, ou uma corrente na Geografia, mas de compreender a Geografia do Trabalho como um campo de investigação focado para o entendimento "da estrutura de poder e do controle social exercido pelo capital sobre a sociedade e, em particular sobre o trabalho" Dessa forma, considera que: "É através do movimento dialético e das mediações teóricas requeridas, que faremos do trabalho um tema permanente para a Geografia".

É nesse contexto que as discussões travadas nesse item visam trazer à tona o debate mais recente sobre a categoria trabalho, enquanto fundante para o debate em Geografia, partindo da realidade dos grupos de estudos, em destaque o Grupo de Estudos em Geografia do Trabalho (UNESP/PP) e o Grupo Estado, Capital, Trabalho e as Políticas de Reordenamentos Territoriais (GEPCT), o primeiro ao apontar a eminência de uma Geografia do Trabalho e o segundo, ao enfatizar, tomando por base a análise de Marx e mais recentemente de Meszáros, o tripé Estado, Capital e Trabalho como central a compreensão da produção do espaço geográfico, portanto o próprio conhecimento da realidade social e histórica. Com base nessas duas leituras, enfatiza-se a relevância do trabalho na produção intelectual atual da geografia, bem como sua repercussão para o pensamento Geográfico brasileiro, em que se pese a centralidade das questões referentes ao mundo do trabalho na compreensão dos diferentes espaços, bem como para a reafirmação da práxis revolucionária de desvendamento das contradições sociais e superação da lógica hegemônica, desumana e totalizante do capital.

Para tanto, a retomada da categoria trabalho, em um contexto de crise estrutural e do processo de reestruturação (econômica, política, social e espacial) do capital torna imprescindível a reafirmação da Geografia crítica, fundamentada na compreensão do mundo do trabalho e na práxis revolucionária do geógrafo.

Para evidenciar a relação capital-trabalho, Thomaz Junior (2002) segue a linha percorrida por Antunes e define que esses são coabitantes de um mesmo processo contraditório, mas, enraizados em esferas diferentes do processo social da produção, um vem a se expressar no outro como elo fundamental de sustentação da contradição. Materializamse sobre bases qualitativamente diferentes. O capital, de um lado, hegemoniza o processo, conformando assim, sob seu controle, a totalidade produtiva. O trabalho, por outro lado, ao 
inserir-se nesse processo, entra subsumido, real ou formalmente, dependendo do desenvolvimento das forças produtivas. Assim, não se perde a dimensão das contradições existentes nesta relação, o que nos leva ao entendimento dos diversos processos de apropriação espacial, que permitem, simultaneamente, uma compreensão da sociedade de classes.

No ano de 2004, Thomaz Junior aponta a necessidade dos geógrafos se debruçarem no entendimento das novas territorialidades engendradas pelo metabolismo do capital, com destaque para a esfera organizativa do trabalho, buscando "apreender o trabalho por meio da leitura geográfica". Para ele há uma complexa trama de relações na compreensão das diversas formas de luta pelo trabalho, que não se restringe as formas das corporações sindicais. Dessa forma, cabe compreender as ações do capital para além do mundo fabril, e o espalhamento das realizações de expropriação/dominação/apropriação do trabalho, inserindo ai assalariados, camponeses, sem-terras, seringueiros, informais, desempregados, etc.. Tornase fundamental nos estudos geográficos sobre o trabalho a compreensão que o metabolismo do capital afeta a vida dentro e fora do labor, ou seja, tanto no âmbito da produção (do trabalho) quanto da reprodução (morada, convívio social). Desse modo,

A Geografia do trabalho deve chamar para si a tarefa de apreender o mundo do trabalho através do espaço geográfico entendido, pois, como uma das características do fenômeno, e da rede de relações categoriais/teóricas/escalares, ou seja, a paisagem, o território e o lugar de existência dos fenômenos, num vai e vem de múltiplas determinações. ( THOMAZ, JUNIOR, 2004, p. 11).

Para tanto, há que se considerar à força destrutiva do capital e a emergência de formas diferenciadas de precarização do trabalho, a que o trabalhador tem se submetido para "vencer os revezes da reestruturação produtiva da capital" e que se expressa na terceirização, precarização, subcontratação, hifenização, desemprego, dentre outras formas. Essas dificuldades concretas vivenciadas pela classe trabalhadora fazem com que, muitas vezes, o camponês - que possui pouca quantidade de terras se desloque para cidade a fim de realizar "algum bico" em determinados períodos do ano, ou ainda se assalariando nas fazendas circunvizinhas, mas sem, nas contradições do modo de produção, perder a sua essência de se manter na terra, processo que em outro texto denominamos de sujeição/reprodução camponesa.

Nesse processo, a mobilidade do trabalho se configura na própria condição de reprodução social buscada pelos trabalhadores. Nesse processo os sujeitos se reproduzem ora 
como camponeses, ora como operários, ou mesmo desenvolvendo diversos tipos de serviços 'autônomos' ou na informalidade, o que efetivamente importa é que disponham seus corpos e suas mentes à produção do valor.

Tal controle sociometabólico do capital tem investido na desmobilização das entidades ligadas aos trabalhadores. Essa realidade é verificável nos estudos de Santos (2009) ao pesquisar o Centro-Sul de Sergipe e Litoral Norte da Bahia, no qual o desemprego estrutural que garante um significativo exército de reserva latente tem levado os sindicatos muito mais a uma ação de intermediação entre o patrão e o empregado, como forma de manter o emprego, ainda que precarizado dos que conseguem permanecer no processo produtivo, em detrimento das lutas e enfrentamentos que outrora representou o papel dos sindicatos no país. Essa realidade também se reproduz nos movimentos sociais e se comprova, por exemplo, no resfriamento da luta pela terra via ocupação, bem como no processo de criminalização de suas estratégias de reprodução. Acredita-se, portanto, que a própria crise estrutural e o desemprego e a precarização das relações de trabalho impostos pela reestruturação da produção, será o estopim da retomada da luta dos trabalhadores por terra, trabalho, direitos e, quiçá, pela superação da ordem hegemônica do capital.

Tal realidade de crise capitalista e da luta pelo trabalho, enquanto condição de reprodução social de centenas e milhares de trabalhadores, em nosso entendimento, valida o debate sobre o trabalho e a centralidade que essa categoria deve ter no âmbito das Ciências Sociais, em geral, e na Geografia, em particular. Por isso, defende-se que o trabalho é o fundamento da mediação sociedade-natureza, dimensão epistemológica central na Geografia, dada sua importância na produção social do espaço geográfico.

Nesse propósito o Grupo de Pesquisa Estado, Capital, Trabalho fundamenta sua análise na leitura da teoria crítica proposta por Marx e retomada por Meszáros, que busca compreender esse momento de crise estrutural do capital que se arrasta desde a década de 1970. Para esse grupo de pesquisa, com sede na Universidade Federal de Sergipe, campus de São Cristóvão, englobando ainda pesquisadores de diversas universidades do Nordeste como: a Universidade estadual do Sudoeste da Bahia (UESB), a Universidade do Estado de Pernambuco (UPE), a Universidade do Estado da Bahia (UNEB) e outras, o processo de produção do espaço geográfico só se torna possível na compreensão da tríade Estado, Capital e Trabalho, em que o contexto de crise estrutural passa a representar novos desafios ao mundo do trabalho, reproduzindo tais desigualdades no espaço geográfico. Portanto o espaço é visto como expressão, produto e condição das contradições do modo de produção ao longo de sua realização histórica, no processo de extração do mais-valor. $\mathrm{O}$ aprofundamento dos 
debates e da produção proposta pelo GPECT será objeto de artigo posterior. Por hora, os pesquisadores interessados podem consultar os trabalhos realizados pelo grupo através do site próprio criado para este fim.

No campo da História do Pensamento, cabe-nos, ainda, apresentar, brevemente, as pesquisas desenvolvidas por Leal (2014) e Menezes (2015), o primeiro ao enfatizar o debate sobre trabalho e técnica no debate geográfico, e o segundo ao buscar compreender como a categoria trabalho foi debatida, ou mesmo negligenciada pelo debate impulsionado pela Geografia, quando a crítica geográfica (ou a busca de um objeto eminentemente geográfico) acaba por se afastar da crítica social, portanto da teoria crítica marxista de superação da sociedade contraditória do capital. Tais leituras, associadas a tantas outras desenvolvidas pelo grupo de pesquisa reafirma o trabalho como categoria fundante do ser social indispensável à compreensão do espaço geográfico enquanto produto e condição da sociedade (nas suas contradições) ao longo do processo histórico.

\section{Referências}

ANTUNES, Ricardo. Os Sentidos do Trabalho: ensaio sobre a afirmação e a negação do trabalho. $6^{\text {a }}$. Ed., São Paulo: Boitempo, 2002.

CONCEIÇÃO, Alexandrina Luz. Jovens andarilhos no curto ciclo do capital. In: Revista OKARA: Geografia em debate. Vol. 1. N. 1. Programa de Pós-Graduação em Geografia, Universidade Federal da Paraíba, 2007.

SOUSA, Raimunda Aurea Dias de. (Org.). Trabalho e trabalhadores: as novas configurações espaciais da reestruturação produtiva no espaço rural. São Cristóvão: Editora UFS, 2011.

SANTOS, Fabrícia de Oliveira. A Natureza Imperialista do Capital e a falácia do fim da crise. São Cristóvão: Editora UFS, 2015.

FRANCESCONI, Léa. Trabalho, tema da pesquisa geográfica. In: Revista Pegada Eletrônica. V. 1 e 2, UNEP Presidente Prudente, 2006.

HARVEY, David. A Justiça Social e a Cidade. Tradução Armando Correa da Silva. São Paulo: Hucitec, 1980.

Condição Pós-Moderna. Tradução Adail Ubirajara Sobral e maria Stela Gonçalves. São Paulo: Edições Loyola, 1993.

Para entender o Capital: Livro I. Tradução Rubens Enderle. São Paulo: Boitempo, 2013.

Para entender o Capital: Livros II e III. Tradução Rubens Enderle. São Paulo: Boitempo, 2014. 
LEAL, Victor Andrade Silva. Trabalho versus técnica na produção histórica do capitalismo. Monografia (Curso de Graduação em Geografia). Departamento de Geografia. Universidade Estadual do Sudoeste da Bahia, 2014.

MARX, Karl. O Capital: Crítica da Economia Política. O Processo de Produção do Capital; V. 1, Tomo 1., $4^{\text {a }}$ ed. revista e editada por Friedrich Engels, 1890. Apresentação de Jacob Gorender; Coordenação e Revisão de Paul Singer; Tradução de Regis Barbosa e Flávio R. Kothe. São Paulo: Abril Cultural, 1983.

MARX, Karl. Manuscritos Econômicos-Filosóficos. Tradução, apresentação e notas de Jesus Ranieri. São Paulo: Boitempo Editorial, 2004.

MENEZES, Sócrates Oliveira. O Trabalho nas Fissuras da Crítica Geográfica. Tese (Doutorado em Geografia). Programa de Pós Graduação em Geografia. Departamento de Geografia. Universidade de São Paulo, 2015.

MÉSZÁROS, István. Para Além do Capital: rumo a uma teoria da transição. Londres: Merlin Press, 1995; São Paulo: Boitempo; Campinas: UNICAMP, 2002.

MOREIRA, Ruy. O que é Geografia. São Paulo: Brasiliense, 1981. (Coleção Primeiros Passos - 48). 1982. (Org.). Geografia teoria e crítica: o saber posto em questão. Petrópolis/RJ: Vozes, As noções do mundo (geográfico) do trabalho. In: Revista Ciência Geográfica. Bauru, n. VIII. Vol. III - (20): Setembro/Dezembro de 2001.

OLIVEIRA, Ariovaldo Umbelino de. A geografia agrária e as transformações territoriais recentes no campo brasileiro. In: CARLOS, A. F. A. (Org.). Novos Caminhos da Geografia. 5. Ed. São Paulo: Contexto, 2007. (Caminhos da Geografia).

OLIVEIRA, Vanessa Dias de. As Tecnologias e suas Interfaces no Campo como Estratégia de Controle do Capital. São Cristovão: UFS-NPGEO, 2007 (Dissertação de Mestrado).

SANTOS, Jânio Roberto Diniz dos. A territorialização dos conflitos e das contradições: o capital versus trabalho nos laranjais baianos e sergipanos. Tese (Doutorado em Geografia0. Universidade de São Paulo. Faculdade de filosofia e Ciências Humanas. São Paulo, 2009.

SILVA, Lenira Rique. A Natureza Contraditória do Espaço Geográfico. 2. ed., São Paulo: Contexto, 2001.

SOUSA, Raimunda Áurea Dias de; CONCEIÇÃO, Alexandrina Luz. A ação do estado na contramão da realização do trabalho. Revista Pegada - vol. 11, n. 2 36, dezembro de 2010.

SOUZA, Suzane Tosta. Da Negação ao Discurso "Hegemônico" do Capital à Atualidade da Luta de Classes no Campo Brasileiro. Camponeses em Luta pelo/no Território no Sudoeste da Bahia. Tese (Doutorado em Geografia). Universidade Federal de Sergipe. Núcleo de pós-Graduação em Geografia. São Cristovão/SE, 2008.

SOUZA, Suzane Tosta; SANTOS, Jânio Roberto Diniz dos. Estado, Capital, Trabalho e as Políticas de Reordenamento Territoriais. Vitória da Conquista/BA: Edições UESB, 2010.

SOUZA, Suzane Tosta; SANTOS, Jânio Roberto Diniz dos; MENEZES, Sócrates Oliveira. Novas Configurações do Espaço Agrário Nordestino. Movimentos e 
Organizações Sociais de luta pela terra e pelo trabalho. Vitória da Conquista/BA: Edições UESB, 2010.

THOMAZ JÚNIOR, Antonio. Por Trás dos Canaviais os “nós” da cana: a relação capital $x$ trabalho e o movimento sindical dos trabalhadores na agroindústria canavieira paulista. São Paulo: Annablume/FAPESP, 2002.

Trabalho Mutante e Territórios em Disputa. In: Revista Pegada. Trabalho e Informalidade. Vol. 8, n. 1. Centro de Estudos de Geografia do Trabalho. Presidente Prudente: CEGET, Junho de 2007.

. Não há nada de novo sob o sol num mundo de heróis! (A civilização da barbárie na agroindústria canavieira). In: Revista Pegada. Modernidade, Barbárie, Classe trabalhadora. Vol. 8, n. 2. Centro de Estudos de Geografia do Trabalho. Presidente Prudente: CEGET, Dezembro de 2007.

THOMAZ JÚNIOR, Antonio (Org.). Geografia e Trabalho no Século XXI. Presidente Prudente: Centelha, 2004. Vol. 1.

THOMAZ JÚNIOR, Antonio (Org.). Geografia e Trabalho no Século XXI. Presidente Prudente: Centelha, 2006. Vol. 2.

Recebido em: 20/09/2017

Aceito para publicação em: 10/10/2017 